result of research and experiment, may be translated into action so far as the public system of education is concerned.

Attention is directed in the first instance to a change during the last century in the conception of the function of government which has exercised a profound influence on the whole theory and practice of administration. This transition is from the idea of the State as essentially a policeman to that of an active promoter and provider of facilities for enabling all citizens to live fuller and happier lives. This change of conception as to function is connected with the abandonment in favour of the idea of human progress of the Platonic principle that any social and political order, however perfect, is bound sooner or later to decay. It is clear that both the nature and the aims of an administrative system which is inspired by the belief that it can and should assist individuals along the road to perfectibility will differ fundamentally from those of one which only hopes to postpone inevitable decay.

The consequence of regarding the State as some kind of universal provider has been a vast increase in the legislative activities of government and has led in turn to greatly increased devolution of executive functions from the central to the local authority. An examination of the capacity of the present local education authorities to cope with their continually increasing burden reveals certain defects, many of which derive from the historical and traditional considerations which have deter. mined the boundaries of English units of local government. In brief, the main defects from which local education authorities appear to be suffering are inherent in their large number and in the great variety in their sizes, resources and the powers delegated to them; the result being possibilities of overlapping, friction and in many cases of almost intolerable financial strain. It is admitted that some of these difficulties are being successfully overcome by co-operation, but co-operation of itself cannot be regarded as an ideal method of administration.

A more serious defect, arising from the same set of circumstances, lies in the increasing difficulty in securing men and women with the necessary time and intelligence to devote to the business of local government. This applies particularly to the unpaid partners in the administrative system. The increase in the demands which the business of local government makes on the time of members of authorities, and the parallel increase in similar demands arising from earning a livelihood, are working together to deprive local bodies of the services of persons in the prime of life and actively engaged in industry and commerce. The type of disinterested administrator on whom local govern- ment was able to rely a generation ago is steadily dying out.

It is recognized that any attempt to remedy these defects may involve changes in the traditional boundaries of local government areas, and would certainly bring the reformer up against that formidable factor known as local patriotism. It is, however, suggested that fewer authorities, with areas and powers more uniform than at present, would not only simplify the problems of administration but would also widen the choice so far as personnel is concerned. A further suggestion is that consideration might be given to modifying the duties performed respectively by members of the committees and their officials with the view of reducing the present calls on the time of the former. Failing this, the only alternative would appear to be to attempt to counteract any deterioration in the amateur element by raising the standard of the professional, although it is realized that any development along these lines would raise a natural suspicion of undue bureaucratic control and would need adequate safeguards in this respect.

\section{A Long-Term Agricultural Policy}

DROF. R. G. STAPLETON, in his presidential address to Section M (Agriculture), stresses the importance of ley-farming in relation to the presentday needs of the nation, and in general he discusses the bearing of systems of farming on the formulation of a long-term agricultural policy. Heurgesthat the needs of the nation must be made to govern the activities of the farmer. In considering national need, it is pointed out that account must be taken of future contingencies, as well as of present requirements. Thus, as well as producing an abundant supply of fresh food, our agricultural policy must take heed of war danger, fall in the population, and the influences of soil erosion overseas. The essential matter is therefore to maintain our acres in a fertile condition, while it is also desirable that we should conduct our farming in such a way as to make possible the maximum of flexibility in commodity production, and to make ourselves altogether less dependent upon imported feeding stuffs.

The main features of the arable, permanent grass, nondescript (much permanent grass and a little arable land per farm) and ley systems are outlined, and it is shown that the arable and ley systems are those which accord best with national needs. Permanent grass allows of the minimum of flexibility, and does not afford the best means of turning grass as such to the most 
profitable account. By adopting alternate husbandry (ley-farming) it is possible to lime land under the plough, which is always the correct way to apply lime, to maintain the fields of the farm in maximum fertility, and to cash the fertility by means that are not wasteful.

Technical details governing the establishment and management of leys for different purposes are considered in some detail, and finally Prof. Stapledon considers the action that is necessary in order in the first place that the present condition of our acres may be accurately gauged, and in the second place, to hasten forward the ploughing up of land in permanent grass that is capable of being used to better advantage. He emphasizes the necessity of conducting a proper survey on a uniform basis on the land itself, particular attention being given to the classification of the acreage in permanent grass and in rough grazings.

The crucial difficulties standing in the way of ploughing up are lack of facilities and lack of working capital. A strong case is made for the extension of credit facilities granted for the explicit purpose of ploughing up and other contingent improvements. It is urged, however, that credit facilities should only be given to carefully selected farmers, and then only to those who will contract to work to an agreed plan over a sufficiently long run of years. Apart from credit facilities, much might be achieved by a re-orientation in the financial and other arrangements made between landlords and tenants, and it is urged that ley-farming, if it became more general, would make it possible to adopt a variety of systems of share farming in directions not at present feasible.

\section{National Parks and the Preservation of the Flora and Fauna of Great Britain}

IN his presidential address to the Conference of 1 Delegates of Corresponding Societies on the use of national parks in Great Britain for the preservation of the fauna, Lord Onslow points out that the term 'national park' covers any natural reserve or open space to which the public have access regardless as to whether it is to be devoted to the preservation of fauna and flora or not, and Lord Onslow discusses methods of utilization of such national parks. The question of the desirability of re-introducing and acclimatizing animals now extinct in Great Britain, such as the reindeer, wild pig, beaver, Irish stoat and lemming, has also to be considered.

Granting the desirability of creating a national park in Great Britain, the first consideration is where to put it. The west coast of Scotland seems to be an ideal spot for such a venture. In those counties there exist thousands of acres of deer forest land, which lends itself readily to the creation of a national park. Such a forest already contains a considerable number of the animals which it is sought to preserve and it may be hoped that others could be acclimatized there. Probably the most attractive animals in a park will be the deer. In Great Britain there are three species of deer-red deer, roe deer, fallow deer. Whether the latter is actually indigenous or was imported at some remote period has not been decided, but if they are not really wild animals, they exist all over the country in a feral state. Other beasts which might well be added to the stock of a national park are the so-called park cattle. These, as is well known, exist in a wild state at Lord Tankerville's estate at Chillingham. The Chartley and Cadzow herds strongly resemble the Chillingham; a herd of these cattle allowed to exist in a wild state would prove a valuable addition to a national park. Then in Scotland there are a few wild goats, which might well be preserved in a national park. Perhaps the most interesting animals would be the carnivorous animais. Foxes, badgers, stoats and weasels are common enough and exist in Scotland as well as in England and Wales. There would be no diffculty about them nor would there be about otters, provided, of course, the park had streams, rivers and burns to provide fish. But there are three species which are becoming very scarce indeed, and deserve every effort being made to retain. These are the wild cat, the pine marten and the pole cat. Perhaps the most difficult beasts to acclimatize in Scotland would be the rarer bats, most of which have only been found in the south of England. Rodents are common enough, so their preservation would present no difficulties.

Turning from mammals to the birds, one may say that if birds are unmolested, generally speaking they will be present, at least those which are suitable to the district. The national park should form a strict bird sanctuary, and if possible part of the park should be near the sea so that sea birds could be encouraged o breed there.

As regards finance, forest country in Scotland is now cheaper than it used to be, and it should be possible to acquire the necessary land for the public generally, either under the Government or by means of public subscription. A national park would not be so expensive to maintain as a deer forest. In the first place there would be an income coming in, as there is in the National Kruger Park, which makes quite a handsome income. There would have to be a hotel or rest house, and roads and footpaths would have to be made so that people could get about and see the animals. 